\title{
Educação, educação matemática e teoria cultural da objetivação: uma conversa com Luis Radford
}

\author{
Vanessa Dias Moretti' \\ Maria Lúcia Panossian" \\ Manoel Oriosvaldo de Mourall!
}

I- Universidade Federal de São Paulo, São Paulo, SP, Brasil.

E-mail: vanessa.moretti@unifesp.br.

II- Universidade Tecnológica Federal do Paraná, Curitiba, PR, Brasil.

E-mail:mlpanossian@utfpr.edu.br

III- Universidade de São Paulo, São

Paulo, SP, Brasil.

E-mail: modmoura@usp.br

\section{Resumo}

Luis Radford é professor titular da Laurentian University em Sudbury, Ontário, no Canadá. Desde 1992, leciona no programa de formação de professores da École des Sciences de l'Éducation, onde é atualmente diretor e coordenador do Laboratório de Pesquisa em Semiótica Cultural e Pensamento Matemático. Professor de Educação da Universidade de Manchester, no Reino Unido, é presidente do Grupo Internacional de Estudos sobre as relações entre a História e a Pedagogia da Matemática, afiliado à International Commission on Mathematical Instruction (ICMI). Autor de diversos artigos científicos nos quais relaciona temas complexos como história, cultura, ensino e aprendizagem, Luis Radford é internacionalmente reconhecido como pesquisador da área da educação matemática, tendo recebido em 2011 a Medalha Hans Freudenthal do ICMI. Na entrevista concedida durante sua estadia no Brasil, em março de 2014, Luis Radford revela alguns de seus caminhos de formação e sintetiza alguns dos elementos e princípios que orientam a Teoria Cultural da Objetivação sobre os processos de ensino e aprendizagem e, em particular, de que forma essa concepção teórica se relaciona com o campo de pesquisa da educação matemática. Na entrevista, são abordadas ainda algumas estratégias e técnicas metodológicas de pesquisa com professores e alunos, em projetos longitudinais que permitem traçar o desenvolvimento cultural da criança. Por fım, o professor Luis Radford aborda questões gerais relacionadas às orientações curriculares no Brasil, compreendido como um país com importante diversidade cultural e social. A leitura dessa entrevista remete à atualidade das pesquisas sobre os processos de ensino e aprendizagem, de forma específica daqueles relacionados ao conhecimento matemático, bem como oferece elementos para a discussão sobre os processos de formação de professores que visem à formação do sujeito em suas máximas potencialidades, ainda que condicionado por determinantes sociais e culturais.

\section{Palavras-chave}

Educação - Educação matemática - Teoria da objetivação - Prática social - Consciência. 


\title{
Education, mathematics education and the cultural theory of objectification: a conversation with Luis Radford
}

\author{
Vanessa Dias Morettil \\ Maria Lúcia Panossian" \\ Manoel Oriosvaldo de Mourall!
}

\begin{abstract}
Luis Radford is a professor at Laurentian University in Sudbury, Ontario, Canada. He has taught in the Education program at The École des Sciences de l'Éducation since 1992, where he is currently director and coordinates the Research Laboratory of Cultural Semiotics and Mathematical Thinking. Education Professor of the University of Manchester in the United Kingdom, he is president of the International Study Group on Relations between the History and Pedagogy of Mathematics, affiliated to International Commission on Mathematical Instruction (ICMI). Author of several scientific articles in which he relates complex topics such as history, culture, teaching and learning, Luis Radford is an internationally recognized researcher in the field of mathematics education, having received the Hans Freudenthal Medal of ICMI in 2011. In an interview during his stay in Brazil, in March 2014, Luis Radford revealed some paths of his education and summarized some of the elements and principles that guide the cultural theory of objectification on the processes of teaching and learning and, in particular, how this theoretical concept relates to the research on mathematics education. He also discussed some strategies and methodological research techniques with teachers and students, in longitudinal projects that allow tracing the cultural development of children. Finally, Professor Luis Radford discussed general questions related to curriculum guidelines in Brazil, understood as a country with important cultural and social diversity. The reading of this interview points to the relevance of research on the processes of teaching and learning, specifically those related to mathematical knowledge, and provides elements for discussion about the processes of teacher education that are aimed at educating subjects to their maximum potential, in spite of social and cultural determinants.
\end{abstract}

\section{Keywords}

I- Universidade Federal de São Paulo, São Paulo, SP, Brasil.

E-mail: vanessa.moretti@unifesp.br.

II- Universidade Tecnológica Federal

do Paraná, Curitiba, PR, Brasil.

E-mail: mlpanossian@utfpr.edu.br

III- Universidade de São Paulo, São

Paulo, SP, Brasil.

E-mail: modmoura@usp.br
Education - Mathematics education - Theory of objectification - Social practice - Consciousness 


\section{Apresentação}

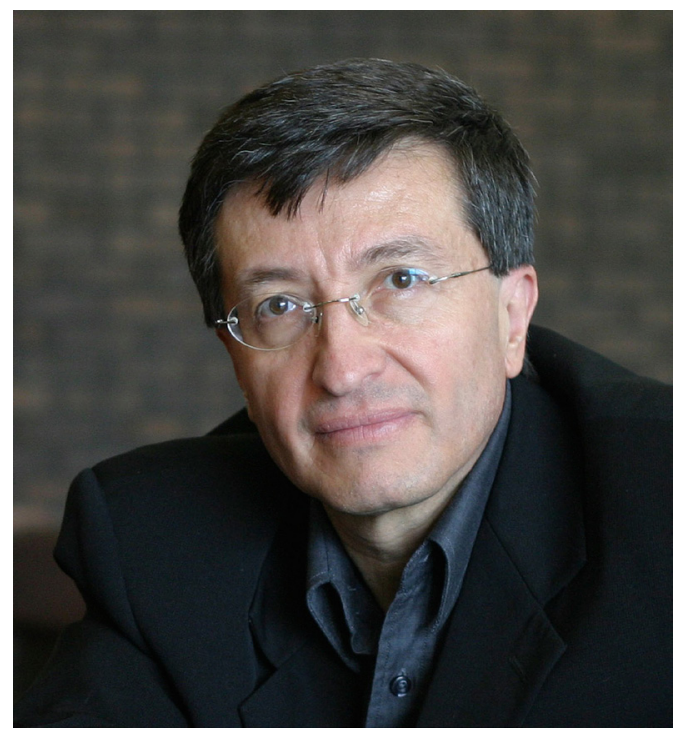

Fonte: arquivos do entrevistado.

O Prof. Luis Radford é professor titular da Laurentian University em Sudbury, em Ontário, Canadá. Desde 1992, leciona no programa de formação de professores da École des Sciences de l'Éducation, instituição na qual é atualmente diretor e onde coordena o Laboratório de Pesquisa em Semiótica Cultural e Pensamento Matemático. Também é professor de educação da Universidade de Manchester, no Reino Unido, e presidente do Grupo Internacional de Estudos sobre as Relações entre a História e Pedagogia da Matemática um grupo afiliado à International Commission on Mathematical Instruction (ICMI). Suas inúmeras publicações entre artigos, capítulos e livros se encontram disponibilizadas na íntegra em sua página pessoal (www.luisradford.ca), garantindo o acesso público às suas produções, que podem ser encontradas em inglês, espanhol, francês e italiano. Autor de diversos livros, Luis Radford foi coeditor de três edições especiais do periódico Estudos e Pesquisas Educacionais em Matemática e também coeditou um número especial da Revista Latinoamericana de Matemática Educativa sobre Semiótica, Cultura e Pensamento matemático (2006). É membro do conselho editorial de várias revistas internacionais, como Mathematical Thinking and Learning, Recherches en Didactique des Mathématiques, Revista Latinoamericana de Matemática Educativa, Avances de Investigación en Educación Matemática.

Em português, encontramos o livro Cognição matemática: história, antropologia e epistemologia, traduzido por Iran Abreu Mendes e Bernadete Morey, pela Livraria da Física (RADF0RD, 2012), que é uma coletânea de dez artigos por meio dos quais podemos reconhecer indícios do movimento do pesquisador no sentido da elaboração da Teoria Cultural da Objetivação. Esses artigos tratam da educação matemática, recorrendo à particularidade da álgebra, fundamentando-se em princípios históricos, bem como nas dimensões da antropologia e epistemologia. A importância do elemento sociocultural é destacada, assim como a relevância da linguagem e das práticas sociais para a produção do conhecimento. Pelo conjunto de suas pesquisas, o professor Luis Radford é internacionalmente reconhecido como pesquisador da área da educação matemática, tendo recebido em 2011 a Medalha Hans Freudenthal da International Commission on Mathematical Instruction (ICMI).

Entre seus temas de estudos e pesquisas, estão os processos de pensamento algébrico, profundamente contemplados em seu desenvolvimento histórico, assim como a relação entre a cultura e o pensamento, a epistemologia da matemática e a semiótica. Aborda em seus trabalhos a semiótica cultural e a cognição humana a partir de uma dimensão antropológica, e considera o papel fundamental da cultura na formação do sujeito, assumindo a práxis social como a base da formação dos processos de conhecimento. Muitos dos seus textos, que são referências para educadores matemáticos brasileiros, tratam da formação do pensamento algébrico em uma perspectiva que supera a abordagem das representações simbólicas. Por meio de uma análise epistemológica, o pesquisador busca 
detectar o que seria o núcleo do saber algébrico, constituído por maneiras analíticas de pensar as quantidades desconhecidas.

Com uma formação inicial de base piagetiana, o professor Luis Radford nos conta nesta entrevista como foi se constituindo seu interesse pelos aspectos culturais e históricos relacionadas às questões do ensino e da aprendizagem da matemática. Nesse percurso, tem encontrado inspiração nos trabalho de Hegel (2003; 2004) e Marx (2004; 2007), bem como no trabalho desenvolvido por todos os intelectuais russos do princípio do século XX, em particular Vygotsky (2001; 2002), Leontiev (1983), Ilyenkov (2008) e Bakhtin (1986). Mais especificamente, suas pesquisas mais recentes têm se apoiado nos referenciais da abordagem histórico-cultural de Lev Vygotsky e na epistemologia cultural de Evald Ilyenkov. Seu trabalho de pesquisa atual concentra-se no desenvolvimento da Teoria Cultural da Objetivação, na qual o problema de ensino-aprendizagem é formulado em torno do conceito de alteridade de Emmanuel Levinas (1976) e Mikhail Bakhtin (1986).

Em março de 2014, Radford esteve no Brasil a convite do Grupo de Estudos e Pesquisas sobre a Atividade Pedagógica (GEPAPe), que é coordenado pelo Professor Manoel Oriosvaldo de Moura. A visita contou com o apoio do Programa de Pós-Graduação em Educação da Faculdade de Educação da Universidade de São Paulo (USP) e do Programa de Pós-Graduação em Educação da Universidade Federal de São Paulo (UNIFESP). Nessa ocasião, o pesquisador desenvolveu um ciclo de atividades de quinze dias, envolvendo pesquisadores de diferentes regiões do Brasil, ciclo esse que foi intitulado "O Processo de Ensino e Aprendizagem a partir da Teoria Cultural da Objetivação”. Durante tal ciclo, apresentou e discutiu a Teoria Cultural da Objetivação, bem como suas relações com conceitos complexos como história e cultura, ensino e aprendizagem, em particular do conhecimento matemático.
Foi nessa oportunidade que Luis Radford nos concedeu esta entrevista, na qual revela alguns dos caminhos de formação responsáveis por sua compreensão acerca das influências culturais sobre o processo de pensamento. Nesta conversa, também sintetiza alguns dos elementos e princípios que orientam a Teoria Cultural da Objetivação sobre os processos de ensino e aprendizagem e, em particular, de que forma essa concepção teórica se relaciona com o campo de pesquisa da educação matemática.

Como revela ao longo da entrevista, a Teoria Cultural da Objetivação é proposta como uma teoria geral sobre ensino e aprendizagem que visa a superar uma compreensão individualista dos processos educativos e, para isso, o pesquisador ressignifica os conceitos de saber, conhecimento e aprendizagem (RADFORD, 2013). Assim, o saber aparece como uma síntese de generalização codificada da ação humana - o trabalho humano -, de modo que, para o aluno, o saber aparece como pura potencialidade. Já o conhecimento é considerado nessa teoria como a atualização do saber e a aprendizagem é compreendida como a tomada de consciência de objetos e sistemas de pensamento que são sintetizados a partir da prática social. Nesse sentido, a aprendizagem está associada ao processo de objetivação, uma vez que objetivar o conhecimento relaciona-se ao encontro entre o subjetivo e o cultural. Tomando como particularidade a relação entre a Teoria Cultural da Objetivação e o ensino de matemática, são focadas as questões relativas ao trabalho conjunto de professores e alunos nas dimensões do saber e do ser, reforçando a aprendizagem como um processo coletivo de aquisição de modos de refletir sobre o mundo, guiados pelas condições epistêmicas, sociais e culturais elaboradas na experiência humana. Para o pesquisador, aprender matemática não é simplesmente aprender a fazer matemática no sentido de resolver problemas, mas aprender a ser em matemática (RADFORD, 2006).

$\mathrm{Na}$ entrevista, são abordadas ainda algumas estratégias e técnicas metodológicas 
de pesquisa com professores e alunos, privilegiando as interações em pequenos grupos e garantindo a coleta de dados por meio de áudio e videogravações, em projetos longitudinais que permitem traçar o desenvolvimento cultural da criança. Por fim, o professor Luis Radford aborda questões gerais relacionadas às orientações curriculares no Brasil, compreendido como um país com importante diversidade cultural e social.
Esperamos que a publicação desta entrevista ofereça novos elementos para a discussão inerente à pesquisa sobre os processos de ensino e aprendizagem e, de forma específica aqueles relacionados ao conhecimento matemático, bem como sobre os processos de formação de professores que visem à formação do sujeito em suas máximas potencialidades, ainda que condicionado por determinantes sociais e culturais.

\section{Referências}

BAKHTIN, Mikhail Mikhailovich. Speech genres and other late essays. Austin: University of Texas Press, 1986.

HEGEL, Georg Wilhelm Friedrich. Logica. Madrid: Folio Espanha, 2003. Trabalho origina publicado em 1830.

HEGEL, Georg Wilhelm Friedrich. The philosophy of history. New York: Courier Dover Publications, 2004. Trabalho original publicado em 1837.

ILYENKOV, Evald Vasilyevich. The dialectics of the abstract and the concrete in Marx's Capital. Delhi: Aakar Books, 2008.

LEONTIEV, Alexis N. Actividad, conciencia, personalidad. Ciudad de La Habana: Pueblo Y Educación, 1983.

LÉVINAS, Emmanuel. Noms propes. Paris: Fata Morgana, 1976.

MARX, Karl. Manuscritos econômico-filosóficos. São Paulo: Boitempo, 2004.

MARX, Karl; ENGELS, Friedrich. A ideologia alemã. São Paulo: Boitempo, 2007.

RADFORD, Luis. Elementos de una teoria cultural de la objetivación. Revista Latinoamericana de Investigación Em Matemática Educativa, p. 103-129, número especial, 2006.

RADFORD, Luis; SCHUBRING, G.; SEEGER, F. Semiotics in mathematics education: epistemology, history, classroom, and culture. Rotterdam: Sense Publishers, 2008.

ROTH, Wolff-Michael; RADFORD, Luis. A cultural historical perspective on teaching and learning. Rotterdam: Sense Publishers, 2011.

RADFORD, Luis. Cognição matemática: história, antropologia e epistemologia. São Paulo: Livraria da Física, 2012.

RADFORD, Luis. Three key concepts of the theory of objectification: knowledge, knowing, and learning. Journal of Research in Mathematics Education, v. 2, n. 1, p. 7-44, 2013.

VYGOTSKY, Lev. Semionovich. A construção do pensamento e linguagem. São Paulo: Martins Fontes, 2001.

VIGOTSKI, Lev Semionovich. A formação social da mente. 6 ed. São Paulo: Martins Fontes, 2002. 
Vanessa Dias Moretti é professora do Departamento de Educação e do Programa de Pós-graduação em Educação da Universidade Federal de São Paulo (Unifesp). Pesquisadora do Grupo de Estudos e Pesquisas sobre a Atividade Pedagógica (GEPAPe) na USP e líder do Grupo de Estudos e Pesquisa em Processos Educativos e Perspectiva Histórico Cultural (GEPPEDH) na Unifesp.

Maria Lúcia Panossian é mestre e doutora em educação pela Universidade de São Paulo. Professora do Departamento de Matemática da Universidade Tecnológica Federal do Paraná (UTFPR) - Curitiba. Membro do Grupo de Estudos e Pesquisas sobre Atividade Pedagógica (GEPAPe) na USP, de História e Epistemologia da Educação Matemática (HEEMa) na PUC-SP e Grupo de Estudos e Pesquisas em Formação de Professores (GEForPro) da Universidade Tecnológica Federal do Paraná (UTFPR).

Manoel Oriosvaldo de Moura é professor titular da Faculdade de Educação da USP. Líder do Grupo de Estudos e Pesquisas sobre a Atividade Pedagógica (GEPAPe) na USP. 


\section{Entrevista}

Professor Luis Radford, queremos agradecer a sua vinda ao Brasil para participar do evento de apresentação da Teoria Cultural da Objetivação aos pesquisadores e estudantes brasileiros e agradecer, em especial, a sua disponibilidade para estar conosco neste momento. Inicialmente, gostaria que nos contasse um pouco sobre seu percurso acadêmico e profissional, destacando o que considera as principais contribuições que influenciaram a sua formação e como foram se constituindo seus interesses de pesquisa.

Meu interesse por educação matemática começou na Guatemala. Eu me graduei em uma faculdade de engenharia e tive oportunidade de trabalhar no departamento de matemática, dando cursos de matemática, e de aprofundar um interesse em entender o ensino e aprendizagem. Esse interesse veio de longe, pois, há muitos anos, tive oportunidade de ir estudar na França e fazer o doutorado, que foi uma experiência muito gratificante, muito grande. Estudei no noroeste da França, numa cidade chamada Estrasburgo, que tinha um instituto de investigação sobre o ensino de matemática, com uma grande influência de Piaget. Assim, minhas primeiras incursões, já como estudante formal de educação matemática, foram nos trabalhos de Piaget, nas investigações que estavam acontecendo então sobre o ensino e a aprendizagem de matemática na França. Eu creio que sempre tive um interesse particular pelas questões relacionadas ao pensamento, e ao pensamento matemático em particular. E minha tese de doutorado trata de questões de pensamento matemático vistas um pouco dessa perspectiva piagetiana. Interessavam-me particularmente as questões de pensamento lógico. Logo tive a oportunidade de regressar à Guatemala e atuei na Universidade Nacional, na Universidade de São Carlos, onde pude trabalhar com um grupo muito forte de companheiros interessados em educação matemática. Trabalhamos na escola de formação de professores do ensino médio. Meus interesses seguiram em torno do pensamento, do pensamento matemático e, já na França, eu sentia necessidade de estudar o pensamento matemático de uma perspectiva um pouco mais geral do que a de estruturas lógicas. Recordo-me que, antes desse tempo, eu tinha uma intuição de que o problema de pensamento não podia se reduzir a um problema de estrutura lógica. Lembro que havia feito um curso de lógica na Universidade de Estrasburgo e tinha perguntado ao meu professor sobre lógica de outras culturas e não pudemos sequer chegar a um acordo em relação à pergunta. Ele não pôde sequer entender o que eu queria dizer quanto à lógica em outras culturas.

Quando regressei à Guatemala, a questão cultural foi me impulsionando com mais força e um dia no México descobri em uma livraria o livro Pensamento e linguagem, de Vygotsky. Li-o e fiz anotações em uma folha, mas não cheguei a me conectar completamente com o livro. Pareceu-me uma obra extraordinária, mas eu não estava suficientemente próximo desse tipo de reflexão para entender a profundidade do livro. Depois, tive a oportunidade de ir ao Canadá e estar de novo exposto a outra cultura - a franco-canadense - e foi muito interessante também implicar-me na cultura e voltar a viver, mas com muito menos intensidade, claro, o choque cultural que significa viver em outro lugar, entre pessoas que pensam completamente diferente. Na França, foi bastante forte, foi um choque incrível. No Canadá, foi menos, em parte por que eu já havia aprendido francês e a língua não era problema. No Canadá, sem dúvida, era uma forma de viver, de ver o mundo muito diferente. Logo, um ano depois, fui trabalhar em Ontário, que é uma província majoritariamente anglofônica e que, como consequência, tem outra visão de mundo, outra forma de pensar. E0, de novo, houve aí um encontro com outra formação cultural e que pôde acentuar a importância das culturas em relação à maneira como vemos no mundo. Penso que essas coisas me levaram a pensar de maneira mais detida a questão da relação 
entre o sujeito e a cultura, e o pensamento e a cultura. Em Montreal, tive acesso à difusão do saber, a livros, revistas, artigos etc., o que foi também muito importante, e me dei conta de que a pergunta que eu tinha feito ao meu professor de lógica em Estrasburgo era uma pergunta que os psicólogos estavam fazendo na chamada psicologia intercultural, que havia proposto uma série de reflexões e perguntas de investigação claramente formuladas, como, por exemplo, sobre universais e a existência de universais nas culturas, ou o problema da relativismo e suas diferentes formulações.

Tudo isso, penso eu, levou-me a ir refletindo sobre o pensamento e o pensamento matemático como algo intimamente ligado à cultura. 0 que quero dizer é que, durante a minha estada em Montreal, tive uma grande oportunidade de trabalhar com uma equipe muito forte de ensino de matemática, que incluía dois historiadores, com os quais passei muito tempo trabalhando, e foi muito importante ver o que os historiadores nos mostravam sobre matemáticas em outras culturas e que eram coisas que se podiam interpretar como não necessariamente redutíveis umas às outras, expressões matemáticas e formas de pensar matemática que eram completamente diferentes umas das outras. Por exemplo, emergiu durante todo esse tempo, durante os anos 1990, uma sensibilidade para pensar o problema de cognição, o problema do ser, de um ponto de vista cultural.

0 senhor indica que o eixo das suas pesquisas recentes tem se organizado com foco no trabalho em sala de aula, numa visão não utilitarista e não instrumental da educação, com vistas a superar discursos pedagógicos entendidos como burgueses, centrados no aluno. Por que o senhor compreende essa centralidade como algo a ser superado e quais são suas fundamentações teóricas para propor tal superação?

A educação nos países ditos avançados, o que quer dizer nos países que têm o controle econômico, segue modelos que lhe são ditados pelo mercado e aparece uma perversão da escola, que passa de uma instituição social e cultural de formação de indivíduos a um centro de capacitação de mão de obra. Parece-me que esse é um grande problema, porque estamos de entrada concebendo o aluno como proprietário privado, como um diretor de empresa potencial, e buscando desenvolver capacidades, habilidades e formas de pensar que são muito reduzidas e que, além disso, despojam o aluno e o professor de toda a subjetividade. Neste afã de querer e de pensar, muitas vezes de maneira inadvertida, o aluno e a escola como um centro de capacitações para os negócios e para o mercado, perdemos de vista toda a dimensão humana. Um dos meus interesses é não somente assinalar isso mas também oferecer pistas de reflexão e pontos de apoio relativamente concretos que permitam repensar a escola, a educação em geral e a educação matemática em particular de outra maneira.

Agora, quais são os fundamentos teóricos que podem embasar tal proposta? Eu tenho encontrado uma grande fonte de inspiração no trabalho de Hegel, Marx e naquele desenvolvido por todos os intelectuais russos do princípio do século XX, em particular Vygotsky, Leontiev, Ilyenkov e também Bakhtin. Afortunadamente, houve uma série de intelectuais que se questionaram sobre o indivíduo, a natureza humana, e muitas dessas perguntas foram formuladas em termos filosóficos, éticos, as quais é muito importante que retomemos do ponto de vista da educação. Todas essas são as bases em que tive que me apoiar para repensar minha tarefa como educador.

Nesse sentido, nós poderíamos compreender que a Teoria Cultural da Objetivação surge como alternativa a essas teorias individualistas neoliberais? Como essa teoria em particular foi se constituindo?

Sim, e talvez tivéssemos de situar o problema dentro do campo da educação matemática, porque 
é nesse campo que eu me movo principalmente, e é o que me serviu de referência para tratar de propor outras coisas. As teorias em educação matemática, as teorias fundamentais sobre as quais essa disciplina se erigiu como uma disciplina científica, o que ocorreu nos anos 1970 e 1980, são teorias que partiram do que a psicologia europeia e a americana podiam oferecer naquele momento, que era essencialmente Piaget. Dessa forma, aparece uma série de reflexões, de ensaios e de tentativas de criação de teorias, das primeiras teorias da educação matemática, que vão adotar as posições psicológicas dominantes na época, das concepções de mente e da epistemologia que Piaget propõe, que, por sua vez, inspira-se na filosofia de Kant - que articula de uma maneira espetacularmente clara a ideia dominante do indivíduo do século das luzes, que é de um sujeito autônomo, autossuficiente, autorregulado, que não vai necessitar mais do que seu entorno para crescer intelectualmente. Há companheiros que começaram nos anos 1990 a introduzir na educação matemática os trabalhos de Vigotsky, e logo de Leontiev, que começaram a assinalar outras opções, outras formas de poder pensar o indivíduo não como alguém isolado, mas como um indivíduo intersubjetivo constituído através de linguagem, das práticas sociais e da sua relação com o outro e com o mundo. Penso em particular nos trabalhos de Stephen Lerman, na Inglaterra, de Mariolina Bartolini Bussi e Alessandra Mariotti, na Itália, e de Paolo Boero, também na Itália. Assim, começa-se a criar um novo espaço para pensar os problemas da educação. Desde então, emerge muito lenta mas progressivamente a ideia de uma formulação teórica inspirada pela teoria da atividade.

Na Teoria Cultural da Objetivação, os conceitos de conhecimento e aprendizagem são entendidos como conceitos chaves? Como o senhor entende o conceito de objetivação e de que forma saber, conhecimento e aprendizagem se relacionam nessa posição teórica?

Talvez um ponto a levar em conta nessa discussão é que, quando se trata de propor uma teoria, ou seja, uma organização sistemática e coerente na medida do possível de aproximação, ao ensino e à aprendizagem, há que se repensar os conceitos fundamentais da educação. Do que disse anteriormente, depreende-se que um dos conceitos problemáticos do ponto de vista histórico-cultural e nas teorias de recorte individualista é precisamente essa concepção insuficiente do indivíduo e da cultura, e do indivíduo em sua relação com a cultura. Aparece todo um esforço para repensar o professor e o aluno, mas ele não é suficiente. Na educação, há mobilizações de saberes, temos que esclarecer também o que entendemos por saber. Em suma, há que repensar os conceitos fundamentais da educação: saber, conhecimento e aprendizagem. Para o construtivismo, que se inspira em Piaget e que adota a posição da produção de saber enquanto produção privada, o saber é aquilo que o sujeito produz. Da mesma maneira que o que o sujeito produz pertence a ele, o que o aluno produz pertence a ele, e isso que pertence a ele é seu conhecimento, é sua aprendizagem. É claro que, se nós consideramos problemática essa posição, temos que ser claros em relação às alternativas que propomos e aos conceitos em que estão baseadas essas alternativas. E foi isso que nos levou a buscar definir o saber de outra maneira. Se não é isso que emana da ação do indivíduo, então o que é o saber? 0 que é conhecer? E como a aprendizagem entra aí? Há um esforço para articular os conceitos que são cruciais quando se quer propor uma teoria de ensino e aprendizagem. Nós partimos de uma ideia hegeliana relacionada ao saber na qual o saber aparece como uma síntese de generalização codificada da ação humana, do trabalho humano. 0 saber, portanto, não é algo inato. 0 saber aparece para o aluno como pura potencialidade, potencialidade cultural. Partimos de uma posição em que adotamos as categorias fundamentais de potencialidade e atualidade e pensamos que o saber que a criança encontra na escola ao entrar nela é simplesmente uma potencialidade. A potencialidade de pensar o mundo de certas maneiras, potencialidades que 
serão atualizadas através da prática social. A primeira distinção entre saber e conhecimento é que o saber é a potencialidade e conhecimento é sua atualização. Evidentemente, a criança não necessariamente pode atualizar esse saber porque não o reconhece. E é aí que entra a ideia de aprendizagem, que é a tomada de consciência das maneiras como se atualiza o saber. E temos tematizado isso, porque era necessário fazê-lo teórica e praticamente dentro da teoria. A aprendizagem é o que temos tematizado como objetivação, ou seja, aqueles processos sociais que fazemos com outras pessoas, cultural e historicamente situados, de reconhecimento de potencialidades culturais que preexistiam no aluno antes de entrar na escola. Em poucas palavras, esses (saber, conhecimento e aprendizagem) seriam os três conceitos ontológicos e epistemológicos importantes da teoria.

Esse processo de tomada de consciência é entendido como essencial para a aprendizagem? Seria possivel apresentar o que, nessa perspectiva, o senhor entende por consciência?

Sim. Como disse antes, era preciso operacionalizar as ideias, porque nós não fazemos filosofia. Nós somos educadores e estamos interessados precisamente em entender as práticas de ensino e aprendizagem. Como se dá a aprendizagem? A maneira através da qual colocamos o problema é a seguinte: assim como há objetos concretos no mundo, há formas ideais que estão constituídas em sistemas de pensamento; da mesma maneira que há cadeiras e mesas quando chegamos ao mundo, esse mundo também está repleto de sistemas de pensamento, de pensamento matemático, de pensamentos artísticos etc., de maneiras de ver o mundo. Tais sistemas de pensamento não são platônicos, mas sim derivados da prática social. São sintetizados a partir da prática social. Então, a maneira de tematizar a aprendizagem é com essa progressiva tomada de consciência dessas idealidades, desses sistemas de pensamentos. Quando falamos de consciência, de tomada de consciência, devemos levar em conta que a consciência não é algo que alguém possui, ou que temos, mas, sim, algo que se forma e que se forma na prática. É consciência de algo. Não há consciência em absoluto. Não há consciência sem objeto. No caso da educação matemática ou para outras disciplinas, esses objetos da consciência são precisamente formas de pensamento que vão ser objeto de consciência através da prática de ensino e aprendizagem. Não é a ideia de consciência no sentido metafísico, da tradição ocidental idealista, mas, sim, uma consciência no sentido dialético-materialista, o que significa consciência com relação ao mundo.

O senhor faz referência à importância da prática social nesse processo de constituição da consciência e tomada de consciência e a suas bases teóricas, como Marx e Leontiev. Quais as influências do conceito de trabalho de Marx e do conceito de atividade conforme apresentado por Leontiev na elaboração da Teoria da Objetivação? E como podemos compreender o conceito de alteridade nessa relação?

Como disse há pouco, a consciência não é algo que se possui; é algo que se forma em nossa relação com os outros, em nossas atividades. Isso põe em evidência o caráter fundamental, como suporte ontológico para a consciência, da natureza da atividade. E uma das ideias fundamentais de Marx é que a consciência é consubstanciada na atividade; ela não antecede a atividade e tampouco deriva da atividade de maneira mecânica. Há de fato uma dialética entre as duas e isso é uma ideia que temos buscado implementar em nossas análises de sala de aula, em nossas reflexões sobre o trabalho do professor, e em nossas reflexões conceituais em termos das formulações e interpretações que propomos na teoria. Aparece-nos de entrada a ideia de consubstancialidade entre consciência e trabalho. Mas o trabalho no sentido marxista, quer dizer, não 
simplesmente aquilo que fazemos para satisfazer nossas necessidades, mas como uma forma de vida que é, por sua vez, expressão do sujeito e constituição do sujeito. Não só expressão no sentido de que é através do trabalho que encontro o meio para expressar o que tenho. Ao expressar-me em atividade, estou procedendo à minha constituição como pessoa e, ao constituir-me como pessoa, estou modificando a atividade de que estou participando. Há toda uma dialética entre esses dois que se tem que entender e que abre possibilidades para compreender, de uma maneira muito diferente e mais profunda, o sentido histórico e cultural do que são os alunos e os professores. Não o aluno como proprietário privado que está negociando significados, nem o professor como assessor financeiro que está dando conselhos para que acumule uma fortuna maior. Como eu disse há pouco, uma das ideias fundamentais da teoria é de que os objetos da consciência nos precedem, os objetos histórica e culturalmente constituídos que encontramos no mundo. Quando dizemos que encontramos, estamos encontrando duas entidades muito diferentes. Por um lado, estamos encontrando as conceitualizações, mas também encontramos o outro. Portanto, a questão da consciência e constituição do sujeito está intimamente ligada à ideia de alteridade, ao reconhecimento desse que não sou eu e que toma dois caminhos: um é o encontro de "aquilo", em inglês, it, e o encontro de "aquele", que em inglês seria you, é o que eu não sou como sujeito, como pessoa, é a outra pessoa que não sou eu. De uma forma muito sensível e definindo numa única linha, a Teoria da Objetivação baseia-se na premissa de alteridade.

Nós gostaríamos de conversar mais especificamente sobre as questões relacionadas com a educação matemática. Tomando a Teoria Cultural da Objetivação como uma teoria geral sobre ensino e aprendizagem, é possível destacar as contribuições específicas dessa teoria para a educação matemática? Em particular, quais seriam suas implicações didáticas e metodológicas para se planejar o ensino da matemática? $\dot{E}$ possível tentar estabelecer essa relação?

Talvez haja contribuições de diferentes naturezas para a educação matemática. Uma é oferecer concepções diferentes do aluno e professor. E, sem dúvida, se eu tivesse que resumir a pergunta da contribuição específica para educação matemática, diria que é uma teoria que sustenta que a educação matemática não deve ser centrada unicamente nos saberes, mas sim também nos seres, e, como tal, coloca uma ênfase muito forte em toda a problemática ao redor da constituição das subjetividades na sala de aula. A teoria permite uma abordagem do problema da subjetivação através de uma ética. E creio que é uma das primeiras teorias em educação matemática a tomar a ética como uma das categorias fundamentais, no mesmo nível daquelas categorias de saber matemático. Nós pensamos profundamente que uma pessoa não pode ser um bom estudante de matemática se se mantém somente como um bom resolvedor de problemas. Eu penso que a questão não é a de transformar o aluno em um resolvedor de problemas, mas, sim, em um sujeito humano. E isso não pode ocorrer sem uma sensibilidade ao outro, sem uma sensibilidade cultural e política. Por isso, dentre as contribuições metodológicas mais importantes que temos feito, não é que tenhamos simplesmente conseguido desenvolver metodologias para analisar o discurso, o gesto, ou a atividade corporal das crianças com minúcia, em análises que às vezes nos levam a estudar vídeos quadro por quadro, foto por foto. Talvez tenhamos feito também contribuições nesse sentido, mas essas, a meu ver, não são as fundamentais.

As contribuições fundamentais são levar a sério a ética e a ideia de que o estudante está ali não somente para aprender mas para ser, transformar-se, converter-se em alguém. Há toda uma metodologia, todo um desenho de sala de aula que a transforma e objetiva torná-la um espaço de debate e de encontros intelectuais e 
afetivos com outras pessoas. Acredito que essa é a contribuição fundamental da teoria, ainda que tenhamos feito contribuições em nível de gestos, significações semióticas, não pelos gestos em si, não pela semiótica em si, mas sim porque, através dos gestos, dos símbolos, das palavras, mobilizamos a criança, que está voltada a um problema e está se relacionando com outras crianças. Através desses meios semióticos, está se expressando a consciência que está formando precisamente nesse momento. Penso que essa é a contribuição mais importante para a educação matemática. Isso é um convite para ver a educação não somente como uma educação de saberes mas também como formação do sujeito como sujeito humano.

Considerando, no contexto da Teoria Cultural da Objetivação, o saber como um conjunto de processos de reflexão e ação encarnados cultural e historicamente, como o estudo da história do conceito pode contribuir para a organização do ensino da matemática?

0 saber como um conjunto de processos de reflexão e ação cultural e historicamente constituídos - como disse antes, esse saber não é uma entidade que aparece sui generis, não é uma entidade que aparece na interação frente a frente com o outro - é algo que sempre tem um antecedente, isto é, para pensar algo, sempre há uma possibilidade já constituída para pensá-lo. Isso não quer dizer que nós continuemos a repeti-lo; isso significa que esse saber tem uma trajetória, uma história e o estudo dessa história, o estudo de suas condições de possibilidades, de transformação, de generalização, de refinamento, dá-nos uma ideia da densidade epistemológica do saber, que pode ser muito importante no momento de desenhar atividades didáticas e interpretar o que se passa na sala aula. Nós utilizamos uma análise epistemológica que nos permite ter uma ideia e conhecer acerca da densidade epistemológica do saber, que possui significações e significados que têm sido sedimentados e refinados no decorrer dos séculos. Pensamos que, sem essa perspectiva histórica epistemológica do saber, arriscamo-nos a não entender as dificuldades que muitos estudantes podem atravessar em seu encontro com essas formas condensadas de refletir e atuar e também perdemos possibilidades para a geração de desenhos sofisticados das atividades que queremos trazer para a sala de aula.

Muitos dos seus textos, que são referências para educadores matemáticos brasileiros, tratam da formação do pensamento algébrico. De que forma seus estudos e investigações históricas e epistemológicas sobre o conhecimento algébrico contribuíram para a compreensão de questões sobre o ensino da álgebra? Podemos considerar já nessas pesquisas uma preocupação com a tomada de consciência que aparece mais recentemente na sua produção acerca dos processos de reflexão e ação historicamente produzidos?

Há alguns anos estou trabalhando na escola primária, em particular nas questões de ensino e aprendizagem da álgebra com crianças muito jovens, de 7 a 8 anos. E, para poder ter alguma possibilidade de levar essas crianças a encontrar formas de pensamento algébrico, era necessário ter uma ideia clara do pensamento algébrico como saber que contém sedimentações conceituais de diferentes níveis de generalidade. E, para mim, foi muito importante a reflexão histórica e psicológica, porque não era possivel começar a ensinar alunos de segundo ano de sete a oito anos, a pensar ou encontrar-se com formas de pensamento algébrico simbólico (quer dizer, um pensamento algébrico baseado em representações alfanuméricas), porque os alunos estavam apenas aprendendo a escrever. Tínhamos que pensar para encontrarmos outras possibilidades e, de certa forma, adotamos uma perspectiva muito diferente. Nossa análise epistemológica nos levou a dar-nos conta de que as principais representações no pensamento algébrico não são realmente as simbólicas, mas sim as formas de pensar analiticamente as 
quantidades desconhecidas, o que poderíamos chamar o centro, o núcleo do saber algébrico. 0 que quero dizer com maneiras analíticas são as maneiras de conseguir deduzir coisas sobre quantidades a partir de uma certa situação que envolve quantidades conhecidas e outras desconhecidas; analítico quer dizer deduzir e foi nesse sentido que os gregos compreenderam. Foi nesse sentido que Pappus ${ }^{1}$ em particular entendeu, e que Viète e os outros algebristas do Renascimento, Cardano e outros, inclusive Descartes retomaram. Essa perspectiva epistemológica nos permitiu criar situações nas quais a escrita não foi central. Quando nós começamos a trabalhar com as classes de segundo ano, com alunos de sete e oito anos, propusemos uma espécie de álgebra oral. Ao invés de pedir que escrevessem ou explicassem o seu raciocínio, demos-lhes máquinas como estas para gravar a voz. Cada equipe tinha uma e falava suas soluções. A questão da representação chegou mais tarde. Esse é um exemplo muito claro de como foi possível tomar consciência do que pensamos ser o núcleo do pensamento algébrico. Através de uma análise histórica e epistemológica, pudemos desenhar atividades de sala de aula nas quais incialmente a escrita não tinha papel primordial, mas sim a palavra. 0 primeiro ano de investigação com uma turma de segundo ano foi um ano de álgebra oral; no ano seguinte, os alunos já haviam desenvolvido certa motricidade e já podiam escrever mais rápido. Então, aproveitamos isso para usar certas representações simbólicas. Mas as primeiras representações são puramente linguísticas, orais. E os alunos chegam a um nível do pensamento algébrico bastante interessante, o que chamamos de pensamentos incorporados através das dimensões sensoriais mistas combinadas. É desse modo que o aluno consegue tomar consciência da forma historicamente constituída de pensar as quantidades desconhecidas e atuar em situações particulares.

1- Papo de Alexandria.
Gostaria de inserir uma pergunta específica ainda sobre álgebra. 0 senhor destaca o papel das quantidades desconhecidas como o núcleo do conhecimento algébrico, mas parece também dizer respeito especificamente a como os alunos tratam a relação que existe entre as grandezas. Nesse caso, como está sendo entendido o papel da variável, da variação, da grandeza variável no estudo histórico e no trabalho com os estudantes?

Evidentemente, o problema da variação é fundamental na matemática e não é por acaso que, quando os matemáticos mais importantes do princípio do século XX começaram a se interessar pelas questões de educação, o conceito fundamental que eles puseram sobre a mesa foi precisamente o de função. 0 conceito de função está baseado na ideia de variável, mas não só no conceito de variável. Baseiase também na covariação dessas variáveis. 0 problema das variáveis e sua variação é muito importante. Agora, isso não necessariamente quer dizer que toda variação ou covariação é algébrica. Pode haver variações e covariações pensadas no campo da aritmética. Então, coloca-se a questão de quais são as diferenças entre as duas formas de pensamento e onde estão as fronteiras entre as duas e qual a relação entre elas. 0 resultado que me parece bastante significativo que conseguimos obter no campo da didática da matemática e, mais especificamente, no campo da álgebra com as crianças é de haver mostrado que podem emergir formas de pensamento algébrico sofisticadas onde as formas aritméticas são bastante simples. Quero dizer que, ao contrário dos currículos tradicionais em que é álgebra começava na escola secundária, uma vez que o pensamento aritmético havia sido desenvolvido com bastante profundidade, agora pensamos que a aritmética não é necessariamente um pré-requisito, pelo menos não no mesmo sentido que tinha há alguns anos. 
Focando agora particularmente os professores, o senhor poderia destacar as principais contribuições ou implicações da Teoria Cultural da Objetivação para o processo de formação docente, em particular de professores de matemática?

Sim, claro. Eu trabalho com a formação de professores e, para ser coerente com os princípios da Teoria da Objetivação, tenho que trabalhar muito com eles não só a dimensão matemática em si, relativa ao saber, mas também a relativa ao ser. Isso implica uma reconceitualização do papel do professor. Digamos que, no construtivismo, o problema é que o professor ficou praticamente sem ofício, dado que era o aluno que tinha que construir seu próprio saber. Dentro da Teoria da Objetivação, visto que partimos de um conceito diferente de saber, como algo que passa de uma pura potencialidade a uma atualização, é dessa atualização que o professor tem que participar juntamente com o aluno para que certas tomadas de consciência sejam possíveis na sala de aula. Nesse sentido, o professor não é um simples acompanhante, coach, ajudador ou assessor. É alguém que está implicadíssimo com o aluno e que sofre ou goza ao lado do aluno. Na formação dos professores, busco fazer meus alunos, que serão futuros professores, compreender que eles não estão ali para inculcar capacidades e habilidades abstratas apreciadas no mercado de trabalho. Eles têm uma missão histórica e cultural a cumprir e, mais do que outra coisa, têm que atender a dimensão do ser. Há uma mudança da orientação e isso não quer dizer que esvaziamos todas as discussões sobre a densidade do saber matemático, as condições que as atividades deveriam atender para ter a maior probabilidade possível de provocar formas de consciência profundas de saberes matemáticos. Evidentemente, tudo isso é importantíssimo, mas a isso está ligada a dimensão ética do sujeito. Penso que essas são as contribuições ou implicações da teoria no processo de formação de professores.
Sobre os procedimentos metodológicos de pesquisa, muitas de suas publicações apresentam exemplos que provêm de sala de aula diretamente. Poderia destacar esses procedimentos metodológicos de suas pesquisas empíricas?

Nossa equipe é constituída de estudantes, de colegas que estão interessados nesse tema, colegas não necessariamente da mesma universidade. Essa equipe também é formada pelos professores que participam de nosso projeto e cujas aulas vamos filmar. Os projetos em que estamos implicados são longitudinais, duram de três a seis anos, o que nos dá a pauta para desenvolver uma metodologia de estudo longitudinal na qual podemos traçar o desenvolvimento cultural da criança. Participam desse projeto diferentes pessoas e nosso ponto de partida é o professor e sua necessidade. 0 professor tem uma obrigação profissional perante a escola, os pais, a família etc. e perante o currículo, o governo. Partirmos do currículo de matemática de Ontário e acompanhamos e apoiamos esses professores através de um projeto conjunto de atividades baseadas nos objetivos do referido currículo. E o que fazemos é propor atividades que são muito mais ricas conceitualmente e não alienantes do ponto de vista do professor e do aluno. Há, antes de ir à sala de aula, discussões periódicas com os professores, que podem ocorrer na escola ou na universidade. Algumas delas são filmadas e outras, gravadas. E aí pensamos juntos as tarefas que vamos dar, depois de ter visto o que crianças fizeram no ano anterior. Analisamos com eles os vídeos, geramos interpretações conjuntamente e novas atividades para levar o aluno a tomadas de consciência mais profundas, quer dizer, a aprendizagens mais profundas do que as que tiveram até o momento anterior. Depois, levamos para a sala de aula quatro ou cinco câmeras e filmamos diferentes grupos. Uma vez que adotamos a natureza social dos saberes e dos seres, propomos espaços de debates de complexidade crescente, que começam com grupos de dois ou três alunos, que trabalham visando a 
resolver certos problemas. Depois, provocamos intercâmbio entre os grupos para que os alunos aprendam a defender suas ideias, a ouvir as dos outros, a tentar entendê-las etc. Depois que filmamos, regressamos ao laboratório e aí passamos a outra etapa, que é de transcrição de vídeos, seleção de passagens importantes relacionadas aos elementos orientadores que temos e que estão apontando os momentos de objetivação e de subjetivação que se deram na sala.

Ainda em relação à Teoria Cultural da Objetivação, quais são suas perspectivas de encaminhamentos de estudos e pesquisas decorrentes?

0 que esperamos fazer nos próximos anos é compreender melhor uma ideia que estamos trabalhando, mas que requer muito mais desenvolvimento, que é a de ensino e aprendizagem vistos não como dois processos diferentes, mas, sim, como um processo conjunto, um mesmo processo, e entender da melhor maneira a questão da dimensão ética, inter-relacional, o que faz ou pode fazer o aluno ir mais adiante do que está indo nesse momento. Há todo um interesse em compreender melhor o que estamos chamando de labor conjunto do professor e do aluno, labor no sentido do materialismo dialético, em entender melhor as formas de produção do saber e as formas de colaboração humana que medeiam o labor conjunto, a fim de distinguir aquelas que se tornam alienação daquelas que oferecem espaço de realização própria e coletiva.

Nós gostariamos de conversar com o senhor sobre algumas questões particulares do contexto educacional brasileiro. No Brasil, embora a legislação educacional faça referência a uma base nacional comum para o currículo da educação básica, a validade e a pertinência de tal base comum é objeto constante de discussão entre pesquisadores da área. Considerando suas formulações sobre o conceito de aprendizagem, entendido como a transformação de modos culturais de reflexão e ação objetivados em objetos da consciência, como o senhor analisa a possibilidade de definição de uma base comum de currículo em um país como o Brasil, com a diversidade que possui?

Creio que o Brasil tem uma dimensão cultural muito particular, no sentido de que é muito diversa, muito rica, muito forte. Todos os países que possuem uma grande cultura estão sendo afetados por uma visão educativa empresarial e creio que isso é um grande risco, ao qual temos que ser muito sensiveis, porque, embora façamos parte de um contexto global, de intercâmbios econômicos gerais, é certo também que cada país tem sua própria especificidade e, à medida que esses pontos básicos podem ser dominados por um imperialismo econômico, corremos o risco muito grande de esquecer precisamente a outra forma de riqueza: a espiritual, a cultural, o que precisamente nos distingue uns dos outros. Nesse sentido, cabe uma importante reflexão de resistência aos mandos de uma educação globalizada e globalizante, em que os seres deixam de ser seres e se convertem em peças de um corpo econômico, que são descartáveis como peças de máquinas. Seria interessante partir de uma perspectiva que justamente reconheça a dimensão histórica e cultural do Brasil, que a avalie e não se deixe levar pelas exigências de uma economia mundial. Não estou dizendo que não se deve participar dessa economia mundial, mas não podemos reduzir isso que se passou nos países avançados, que são avançados sim economicamente, mas não muito avançados em outros aspectos, em aspectos humanos em particular. Há um grande risco de perder uma riqueza que temos na América Latina, por seguir uma tendência cega de avanço pessoal e material unicamente. Eu gostaria muito, por exemplo, que fosse levada em conta uma dimensão ética, de valorização da cultura e da história, da sensibilidade ao outro, uma sensibilidade à injustiça social, não do ponto de vista tolerante geral, mas precisamente de reflexão sobre os mecanismos de sua produção. 
Na sua avaliação, um currículo de Matemática que considere esses últimos elementos, inclusive a diversidade cultural brasileira, seria pertinente com a existência de conhecimentos ou conceitos acordados dentro de um currículo nacional de base comum?

0 problema por trás disso, creio eu, é a maneira como o currículo opera. 0 currículo não deve ser prescritivo no sentido de normalidade opressiva. 0 currículo deve ser um ponto de referência. Mais do que um documento a seguir, um currículo deveria ser um ponto de partida para que os indivíduos em certas localidades, em certas comunidades, reflitam a respeito deles e do mundo. Um currículo é um artefato impulsionado por duas forças opostas. Por um lado, uma força centrípeta, que busca identificar elementos comuns (ideias, conceitos, maneiras de fazer, maneiras de ser); por outro lado, uma força centrífuga, que aponta a diferença. Nesse sentido, um currículo é um artefato dinâmico, portador de tensões. Essas tensões fazem parte da natureza do currículo $\mathrm{e}$, sem elas, ele não poderia ser um artefato cultural genuíno, crítico, aberto e suscetivel de ser transformado continuamente. 0 problema é que, em geral, o currículo tem sido visto como uma entidade fechada, estática e tem se transformado em um instrumento de controle, constituindo-se em receita, em uma série de passos a ser seguidos.

0 problema não é tanto que haja ou não haja um currículo. Pode haver ou não haver essa definição de elementos comuns no currículo. 0 que importa é o sentido crítico que daremos a esses elementos. Deveria haver, por exemplo, no caso da matemática, toda uma reflexão sobre a riqueza matemática que existe no Brasil, a qual é evidenciada, por exemplo, pela etnomatemática. São formas de pensar diferentes, são formas de pensar o mundo de outra maneira. Em nosso imperialismo ocidental, temos nos deixado levar pela ideia de uma matemática que, desgraçadamente, tornou-se utilitarista e simplesmente um cálculo. Não há espaço para o prazer estético e o crescimento subjetivo. Já não há espaço para a comunicação das ideias através de certos símbolos, de certos procedimentos. No Canadá, não existe um currículo de base comum; o currículo é provincial. É a província que é responsável por seu currículo. Ainda assim, o currículo é visto como um documento oficial que contém uma série de ordens que é necessário executar; não é um elemento de reflexão para nada. 0 problema com a matemática é que se tornou meramente utilitarista e que tudo aquilo que não é suscetível de ser traduzido em termos econômicos não entra. Há um currículo, mas com uma discriminação entre o que é digno de ser aprendido ou não. É um currículo necessariamente excludente. Mas poderia se pensar em um currículo aberto, um currículo reflexivo, um currículo que ofereça uma possibilidade de reflexão que permita ouvir outras coisas também.

Ainda sobre a educação brasileira, em particular sobre a educação matemática no Brasil, o senhor poderia destacar alguma particularidade que considera relevante e de que forma essa particularidade poderia ser interpretada por meio da Teoria Cultural da Objetivação?

Creio que está relacionada ao que dizíamos. Eu penso que o Brasil é um dos poucos paises do mundo que tem a possibilidade de oferecer uma diversidade incrivel de formas de pensar matematicamente o mundo. Isso é uma contribuição inestimável da educação matemática brasileira, que tem a ver com a própria estrutura do país, sua própria história etc. e isso é algo muito valioso do ponto de vista da compreensão do que somos como seres humanos e a partir do que poderíamos aprender muito. Existem formas matemáticas de pensar o mundo que não estão guiadas simplesmente para fazer cálculos. Filósofos importantes como um Heidegger, como Hegel, lamentaram em seu momento a mudança tecnológica utilitarista e calculista que estava tomando a matemática que eles conheceram. $\mathrm{Na}$ matemática contemporânea, talvez o mais dramático seja o esvaziamento do sujeito e a crítica que Hegel faz precisamente à matemática é que não há sujeito. 
Para finalizar, o senhor gostaria de abordar ou comentar algum tema que não foi contemplado nessa nossa conversa?

Não, creio que cobrimos muito bem os temas mais importantes, e que a entrevista foi muito bem estruturada.
Professor, gostaríamos de agradecer a sua disponibilidade e tenho certeza de que a sua fala e as suas reflexões poderão contribuir e servir de referência de forma bastante significativa para a pesquisa em educação, e para a pesquisa em educação matemática, em particular no Brasil. Muito obrigado!

\section{Bibliografia do entrevistado}

\section{Livros}

RADFORD, Luis. Cognição matemática: história, antropologia e epistemologia. São Paulo: Livraria da Física, 2012.

\section{Livros em parceria}

RADFORD, Luis; DEMERS, Serg. Communication et apprentissage: repères conceptuels et pratiques pour la salle de classe de mathématiques. Ottawa: Centre Franco-Ontarien des Ressources Pédagogiques, 2004.

RADFORD, Luis; DEMERS, Serg; MIRANDA, Isaias. Processus d'abstraction en mathématiques. Ottawa: Centre Franco-Ontarien de Ressources Pédagogiques, Imprimeur de la Reine pour l'Ontario, 2009.

RADFORD, Luis; SCHUBRING, Gert; SEEGER, Falk. Semiotics in mathematics education: epistemology, history, classroom, and culture. Rotterdam: Sense Publishers, 2008.

ROTH, Wolff-Michael; RADFORD, Luis. A cultural historical perspective on teaching and learning. Rotterdam: Sense Publishers, 2011.

\section{Capítulos}

RADFORD, Luis. Cultura e historia: dos conceptops dificiles y controversiales en aproximaciones contemporaneas en la educación matemática. In: MENDES, Iran; FARIAS, Carlos Aldemir (Orgs.). Práticas socioculturais e educação matemática. São Paulo: Livraria da Física, 2014. p. 49-68.

RADFORD, Luis. On teachers and students: An ethical cultural-historical perspective. In: LILJEDAHL, Peter; et al. (Orgs.). Proceedings of the joint meeting of PME 38 and PME-NA 36 (Plenary Conference), Vancouver: PME, 2014. p. 1-20.

RADFORD, Luis. Bakhtin, alterity, and ideology. Commentary on the chapter by richard barwell, "heteroglossia in multilingual mathematics classrooms." In: FORGASZ, Helen; RIVERA, Ferdiand. (Orgs.). Towards equity in mathematics education: advances in mathematics education. Berlin: Springer-Verlag, 2012. p. 339-342.

RADFORD, Luis. The cultural-epistomological conditions of the emergence of algebraic symbolism. In: FURRINGHETTI, Fulvia; KAIJSER, Sten; TZANAKIS, Constantinos. Proceedings of the 2004 history and pedagogy of mathematics conference \& ESU4, Uppsala, Sweden, (Plenary Lecture), 2006, p. 509-524.

RADFORD, Luis. How to look at the general through the particular: Berkeley and Kant on symbolizing mathematical generality. In: 
SBARAGLI, Silvia. La matematica e la sua didattica: vent'anni di impegno. Roma, 2006. p. 245-248.

RADFORD, Luis. En torno a tres problemas de la generalización. In: RICO, Luis; et al. (Orgs.). Investigación en didáctica de las matemáticas: homenaje a Encamación Castro. Granada: Editorial Comares, 2013. p. 3-12.

RADFORD, Luis. Signifying relative motion: time, space and the semiotics of Cartesian graphs. In: ROTH, Wolff-Michael (Org.). Mathematical representations at the interface of the body and culture. Charlotte: Information Age Publishers, 2009. p. 45-69.

\section{Artigos em periódicos}

RADFORD, Luis. Algebraic thinking from a cultural semiotic perspective. Research in Mathematics Education, v. 12, n. 1, p.1-19, 2010.

RADFORD, Luis. De la teoría de la objetivación. Revista Latinoamericana de Etnomatemática, v. 7, n. 2, p.132-150, 2014.

RADFORD, Luis. Education and the illusions of emancipation. Educational Studies in Mathematics, v. 80, n. 1, p. 101-118, 2012.

RADFORD, Luis. Elementos de una teoria cultural de la objetivación. Revista Latinoamericana de Investigación em Matemática Educativa, número especial, p. 103-129, 2006.

RADFORD, Luis. La transformación de una teoría matemática: el caso de los números poligonales, Mathesis, v. 11, n. 3, p. 217250, 1995.

RADFORD, Luis; D'AMORE, Bruno; BAGNI, Giorgio. Obstáulos epistemológicos y perspectiva socio-cultural de la matemática. Colección Cuadernos del Seminario en Educación. Universidad Nacional de Colombia, Bogotá, D.C., v. 10, p. 5-25, 2007.

RADFORD, Luis. On the development of algebraic thinking. PNA, v. 64, n.1, p. 117-133, 2012.

RADFORD, Luis. The anthropological turn in mathematics education and its implication on the meaning of mathematical activity and classroom practice. Acta Didactica Universitatis Comenianae. Mathematics, n. 10, p.103-120, 2010.

RADFORD, Luis. Three key concepts of the theory of objectification: knowledge, knowing, and learning. Journal of Research in Mathematics Education, v. 2, n. 1, p. 7-44, 2013.

ROTH, Wolff-Michael; RADFORD, Luis; LACROIX, Lionel. Working with cultural-historical activity theory. Qualitative Social Research, v. 13, n. 2, 2012.

ROTH, Wolff-Michael; RADFORD, Luis. Re/thinking the Zone of Proximal Development (Symmetrically). Mind, Culture, and Activity, v. 17, n. 4, p. 299-307, 2010. 
Tradução / Translation

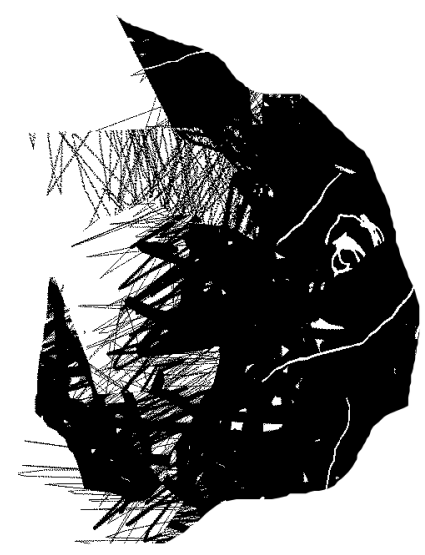

